\title{
BMJ Open How should health policy and practice respond to the increased genetic risk associated with close relative marriage? results of a UK Delphi consensus building exercise
}

\author{
Sarah Salway, ${ }^{1}$ Edanur Yazici, ${ }^{1}$ Nasaim Khan, ${ }^{2}$ Parveen Ali, ${ }^{3}$ Frances Elmslie, ${ }^{4}$ \\ Julia Thompson, ${ }^{5}$ Nadeem Qureshi ${ }^{6}$
}

To cite: Salway S, Yazici E, Khan N, et al. How should health policy and practice respond to the increased genetic risk associated with close relative marriage? results of a UK Delphi consensus building exercise. BMJ Open 2019;9:e028928. doi:10.1136/ bmjopen-2019-028928

\section{- Prepublication history for} this paper is available online. To view these files, please visit the journal online (http://dx.doi. org/10.1136/bmjopen-2019028928).

Received 3 January 2019 Revised 11 April 2019 Accepted 10 May 2019
Check for updates

(C) Author(s) (or their employer(s)) 2019. Re-use permitted under CC BY-NC. No commercial re-use. See rights and permissions. Published by BMJ.

For numbered affiliations see end of article.

Correspondence to

Dr Sarah Salway;

s.salway@sheffield.ac.uk

\section{ABSTRACT}

Objectives (1) To explore professional and lay stakeholder views on the design and delivery of services in the area of consanguinity and genetic risk. (2) To identify principles on which there is sufficient consensus to warrant inclusion in a national guidance document. (3) To highlight differences of opinion that necessitate dialogue. (4) To identify areas where further research or development work is needed to inform practical service approaches.

Design Delphi exercise. Three rounds and one consensus conference.

Setting UK, national, web-based and face-to-face.

Participants Recruitment via email distribution lists and professional networks. 42 participants with varied professional and demographic backgrounds contributed to at least one round of the exercise. 29 people participated in statement ranking across both rounds 2 and 3 .

Results 0ver 700 individual statements were generated in round 1 and consolidated into 193 unique statements for ranking in round 2, with $60 \%$ achieving $80 \%$ or higher agreement. In round 3, 74\% of statements achieved $80 \%$ or higher agreement. Consensus conference discussions resulted in a final set of 148 agreed statements, providing direction for both policy-makers and healthcare professionals. 13 general principles were agreed, with over $90 \%$ agreement on 12 of these. Remaining statements were organised into nine themes: national level leadership and coordination, local level leadership and coordination, training and competencies for healthcare and other professionals, genetic services, genetic literacy, primary care, referrals and coordination, monitoring and evaluation and research. Next steps and working groups were also identified.

Conclusions There is high agreement among UK stakeholders on the general principles that should shape policy and practice responses in this area: equity of access, cultural competence, coordinated inter-agency working, co-design and empowerment and embedded evaluation. The need for strong national leadership to ensure more efficient sharing of knowledge and promotion of more equitable and consistent responses across the country is emphasised.

\section{Strengths and limitations of this study}

- A key strength of this Delphi study is its novelty; it is the first study globally to examine stakeholder opinions on how policy and practice should be developed in this area of need.

- A wide range of participants was recruited and retained, generating and subsequently ranking a comprehensive set of statements.

- The inclusion of a deliberative, consensus conference was also a strength, increasing the likelihood that the achieved set of principles will provide an effective platform for subsequent action.

- The participation of just one patient/public representative was a limitation and future work must ensure meaningful inclusion of patient and public perspectives.

- A further limitation was the persistence into round 3 of some statements that lacked clarity.

\section{INTRODUCTION}

The practice of marrying close blood relatives, commonly cousins, is socially acceptable in many communities around the world. However, blood relatives are more likely to carry the same gene variants than unrelated people, resulting in a higher incidence of autosomal recessive genetic disorders among births in populations where consanguineous marriage is customarily practised compared with those in which reproductive partners are typically unrelated. Though accurate estimates of the size of increased risk are compromised by unconfirmed diagnoses and pregnancy terminations, studies across varied settings suggest that the incidence of any congenital anomaly is typically two to three per 100 births among unrelated couples compared with five to six per 100 births among first cousin couples. ${ }^{1-3}$ This increased 
risk translates into higher levels of morbidity, infant and child mortality. While recognised globally as a health concern for decades, ${ }^{4-6}$ recent years have seen increased attention among medical professionals, researchers and the public in England and other European countries that are home to sizeable minority ethnic populations of Asian and Arab origin. ${ }^{7-11}$

A growing body of research is improving understanding of the factors shaping risk and potential service responses. Low knowledge and poor service uptake among people at risk of recessive conditions are repeatedly highlighted in England and elsewhere. ${ }^{12-16}$ Studies have found that the provision of knowledge about recessive genetic inheritance among affected families can be empowering, but that services are commonly ill-coordinated and access to specialist genetic healthcare is patchy. ${ }^{13} 1417$ Mistrust in health practitioners among members of affected communities and a perception that services lack cultural sensitivity are also documented. ${ }^{18}$ Understanding of, and skills to respond to, the issue are poor among many healthcare professionals. $^{1319}$

Vigorous - frequently polarised - debate regarding appropriate policy and practice responses has been reported among the UK medical profession, in the media, and at community level ${ }^{20-27}$ Some argue that close relative marriage is outdated and that policy, or even legislation, is needed to curb this practice. In contrast, others maintain that such approaches are stigmatising and ineffective. ${ }^{132}$ Parallels have been drawn with the rising age at childbirth among well-educated White British women and the associated increased risk of chromosomal disorders. Why - it is asked - does one cultural practice attract condemnation while the other has prompted developments in foetal testing, patient education and service delivery? Observers have also highlighted recommendations from the Eastern Mediterranean Regional Office of the $\mathrm{WHO}^{28}$ for family-centred genetic services for at-risk families, alongside health professional training and community level genetic literacy interventions. ${ }^{29}$

National policy has acknowledged the need to address genetic risk associated with consanguinity in England ${ }^{30-32}$ and several local service responses have emerged in recent years. ${ }^{12} 3334$ However, a formative review ${ }^{20}$ found these local initiatives to be largely uncoordinated and very varied in detail, scope and level of investment. To date, there has been no national-level development of policy, guidelines or resources to support service commissioners, healthcare professionals or the public in understanding and responding to this issue in England. This vacuum encourages the development of inconsistent - and potentially ineffective or even harmful - service initiatives in different areas of the country and fails to ensure the efficient generation and sharing of knowledge. ${ }^{1321}$ Elsewhere in Europe the picture appears to be even less advanced. ${ }^{27}$

We report here on a structured Delphi consensus building exercise that aimed to provide much needed direction to healthcare policy-makers and practitioners in England and other countries.

\section{OBJECTIVES}

1. To explore professional and lay stakeholder views on the design and delivery of services in the area of consanguinity and genetic risk.

2. To identify principles on which there is sufficient consensus to warrant inclusion in a national guidance document.

3. To highlight issues where inter-professional differences of opinion necessitate further debate and dialogue.

4. To identify areas where further research and/or development work is needed to develop principles into practical service approaches.

\section{METHODS \\ Design}

The Delphi method is used to build consensus in expert opinion in an iterative and structured way ${ }^{35} 36$ and has been deployed in relation to varied aspects of health service design and provision. ${ }^{37} 38$ The present exercise was conducted between March and July 2018 using three rounds of online consultation, followed by a face-to-face consensus conference.

In Round 1, participants were asked to provide statements that captured the key principles or elements of service design and delivery that they considered to be important in relation to responding to the genetic risk associated with customary consanguineous (close blood relative) marriage. An online form provided participants with 13 prompting headings plus an open-ended section and submissions remained open for 2 weeks. Responses were collated and reviewed independently by two researchers (SS and EY) to identify duplicate and ambiguous statements, and to organise the statements into themes. Working together, the two researchers next developed an agreed coherent set of statements based around thematic areas. In two cases the participants were contacted to seek clarity on the meaning of a contributed statement. The statements were shared with two other team members (PA and NK) to check clarity of wording only, and this resulted in a number of minor changes. All unique statements were taken forward to the second round.

In Round 2, participants were asked to rank each of the statements on a 7-point Likert scale ranging from 'very strongly disagree' to 'very strongly agree'. Participants were given the opportunity to select 'I don't know' for each statement and to skip entire sections if they felt insufficiently well informed to rank the statements. Participants could also provide open-ended comments on any of the statements. Round 2 remained open for 2 weeks. The weighted mean of responses for each statement (where 'very strongly disagree' was 1 and 'very strongly agree' was 7), and the percentage of participants who agreed with the statement ('agree', 'strongly agree' or 'very strongly agree') were calculated. Graphs illustrating the spread of responses were produced and inspected. 
In Round 3, all participants from Round 2 were sent individualised feedback with summary tables listing for each statement (i) their own response, (ii) the weighted average, (iii) the percentage of all participants who agreed and (iv) the percentage who responded 'don't know'. Based on this information, they were invited to re-rank each of the statements. Participants were reminded that they could stick to their original ranking if they so wished. Open-ended feedback from Round 2 was reviewed and minor amendments made to ensure statement clarity. Round 3 remained open for 2 weeks. Summary statistics were again produced. In addition, responses for each statement were examined within subgroups of respondents - those identifying their ethnicity as 'Asian/Asian British Pakistani' versus those identifying as 'White English/Welsh/Scottish/Northern Irish/British' and those identifying their area of work as 'public health' versus all those identifying with another area of work.

A half-day consensus conference (CC) was next convened to discuss the findings. A consensus conference encourages dialogue, can foster a sense of ownership and can be useful in identifying appropriate strategic direction. ${ }^{38}$ Participants were first provided with an overview of how the exercise had been conducted and the levels of participation and agreement achieved. Next structured discussion took place around the statements. We took $80 \%$ agreement or $80 \%$ disagreement as our cut-off for consensus. Previous Delphi exercises have defined consensus as being from anywhere between $50 \%$ and $97 \% .^{38}$ First, the whole group were led in a discussion around six strategic level statements that had failed to achieve consensus. Subsequently, small group discussions focused on the results in each of the other thematic areas (except the research-related statements, which were cross-referenced by all groups). Discussions were focused on whether lack of consensus reflected (i) poor wording or potential misunderstanding, (ii) a lack of evidence to support or refute the statement or (iii) genuine differing perspectives and opinions on the issue. Further, the groups considered whether the lack of current consensus was likely to be an obstacle to making progress towards national policies, standards and resources and, if so, what the appropriate next step would be. Participants also discussed areas of consensus in order to identify those that required more research or development work to be incorporated into guidance and how the final principles and recommendations might be mobilised to inform policy and practice. Detailed notes were taken in all of the groups. A plenary session shared the key messages and identified areas of future action.

\section{Recruitment}

Participants were invited to participate in the exercise via emails sent to both targeted and more generic email lists (including lists relating to prior relevant events, public health and genetic counsellor professional lists and minority-ethnic-health@jiscmail.ac.uk). A number of public contributors were also invited to participate via direct invitation from research team members. Invitation emails included an information sheet and a direct link to the online survey tools. Participants were invited to contribute to all three online rounds and the final consensus conference.

\section{Patient and public involvement}

The general plans for the study were discussed via the Sheffield Community Genetics Working Group, which includes representatives of the affected communities alongside healthcare practitioners and commissioners, and with one public contributor in a one-to-one meeting. There was no direct patient or public involvement in the design of the Delphi exercise nor in the analysis or this write up of the results. A lay version of the results was prepared and shared through a series of consultation meetings with public and patient contributors in four localities and involving over 20 people who identified as belonging to a community affected by this health issue.

\section{RESULTS}

\section{Participants}

Figure 1 summarises the stages of the Delphi exercise and the numbers of participants in each round. Overall, 42 people participated at any stage of the process, with 29 participating in rounds 2 and 3 , and 16 in the entire exercise including the face-to-face workshop. Table 1 shows the socio-demographic and work-related characteristics of participants. A wide range of professional roles and work areas were represented, though public health was the most common speciality. Respondents identified with a range of ethnic groups.

\section{Round 2}

Taking the cut-off for consensus as $80 \%$ or greater in favour of a statement, or below $20 \%$ for agreed rejection, there was consensus overall on 115 out of 193 statements $(60 \%)$ in Round 2. The numbers of statements achieving consensus varied across the 10 themes after Round 2: general principles 10/12, national level leadership and coordination $7 / 16$, local level leadership and coordination $7 / 11$, training and competencies for healthcare and other professionals $8 / 16$, genetic services $20 / 27$, raising genetic literacy $14 / 26$, primary care $4 / 10$, referrals and coordination between services $6 / 12$, monitoring and evaluation of services 22/36 and research 17/27.

\section{Round 3 and consensus conference}

As a result of the open-ended feedback to the statements in Round 2, three statements were amended to improve clarity in Round 3, while two statements were split into two separate statements, and seven new statements were included, resulting in a total of 202 separate statements in Round 3.

Table 2 (panels A-J) present the findings from both rounds, together with the summary recommendation from the CC discussions, for each thematic area. 


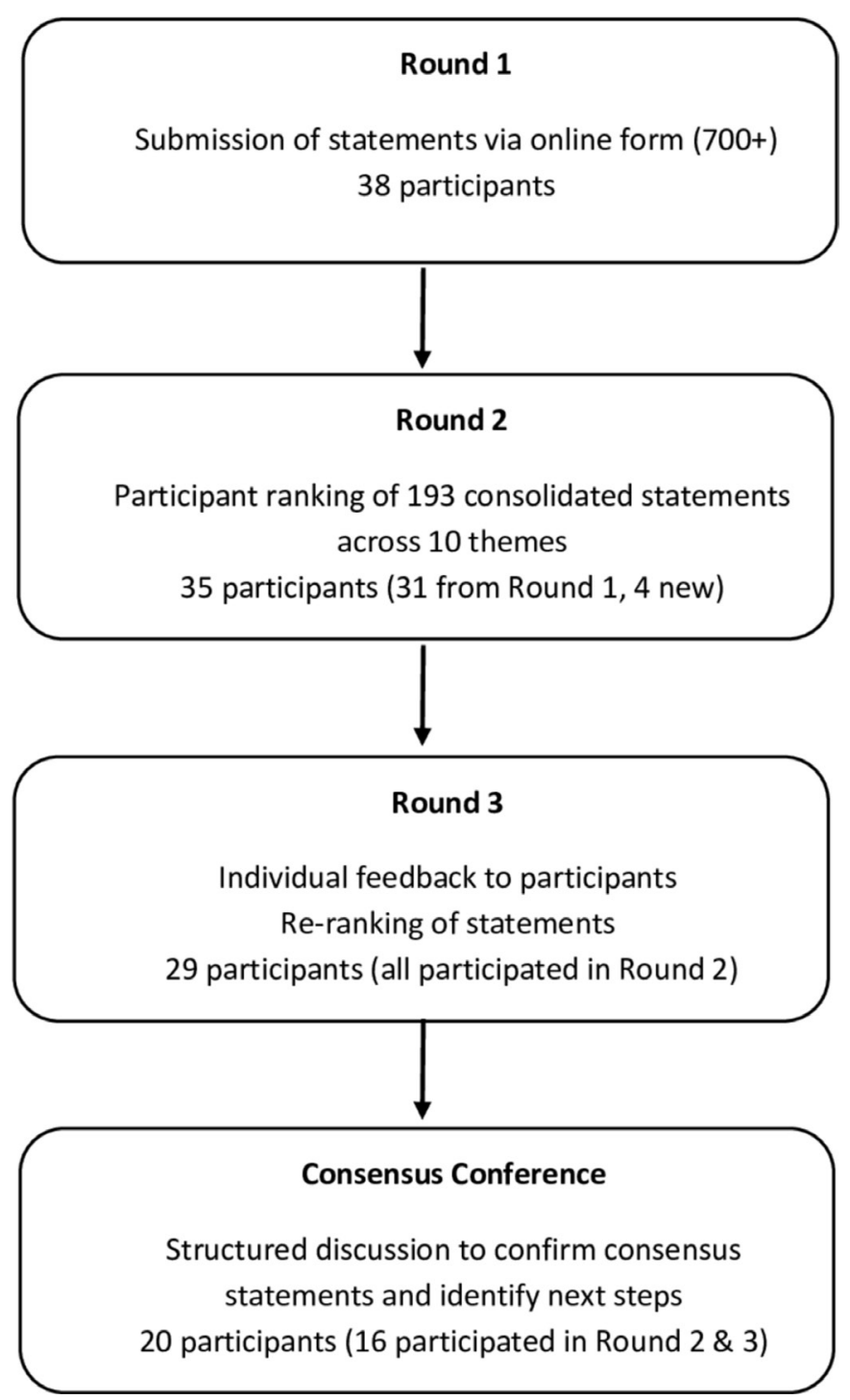

Figure 1 Delphi exercise process.

Overall, the number of statements achieving consensus increased between Round 2 and Round 3, with 148/202 statements $(73 \%)$ having $80 \%$ or higher agreement in Round 3 (or less than $20 \%$, indicating agreed rejection). In almost all cases the shift in response distribution across the two rounds was small. Patterns of consensus remained varied across the thematic areas. The addition of several new statements was helpful in achieving greater consensus on some issues. In Round 3, responses to two statements were found to show important variation between the ethnic categories, while two showed important variation between 'public health' respondents and others; as discussed below.

\section{General principles}

Round 3 responses demonstrated very high levels of agreement on the general principles statements, with all except one of the statements achieving over $80 \%$ agreement (or rejection in the case of A6, 'This is not a professional issue, it is a community issue...), and 12 out of 15 over $90 \%$. The core message from these statements is that national action, framed in terms of equity of access to culturally competent services, is urgently needed. Round 3 saw the introduction of statement A11b (90.3\% agreement), which acknowledges the need for local variation in service responses but affirms that such variants should take place within a national framework.

A9 - 'Sensitivities should be understood as arising from a dominant culture that regards close relative marriage as incestuous and places a value judgement on the practice, and not from consanguineous communities themselves' - was the only statement on which there was a lack of agreement. Discussion on A9 took place at the consensus conference and included the individual who initially proposed this statement. The statement was considered too complex by some participants. The core intention of the statement was clarified as to highlight the problem that minority needs are frequently constructed as illegitimate and repeatedly overlooked in policy and practice, or else responded to in ways that are stigmatising. It was agreed that this statement could be removed as other consensus statements suffice to convey this important concern.

National level leadership and coordination

In Round 3, 12 out of 17 statements relating to national leadership achieved consensus. The inclusion of statement B2a - which called for both NHS England (NHSE) and Public Health England (PHE) to take on a national leadership role - was found to address the low level of agreement with statements $\mathrm{B} 1$ and $\mathrm{B} 2$, indicating that respondents were reluctant to place responsibility with either one of these national agencies alone.

Consensus conference discussions confirmed that participants believed that both NHSE and PHE needed to be involved in leading a national level response, with good coordination between these agencies. In addition, however, participants emphasised that the Department for Health and Social care (DHSC) should provide the overall steer so that these national agencies have a clear mandate to develop this area of work. Similarly, statement B11, which called for PHE to organise knowledge sharing events, lacked consensus at Round 3, but discussion in the conference confirmed that this was because respondents wanted to emphasise joint responsibility and a coordinated approach to allocating roles across agencies.

Responses to B12 - 'National leaders should combat the poor sustainability of investments in this service area'- lacked consensus (67.9\% agreement) at the end of Round 3, and discussion in the conference suggested that this reflected a combination of both a lack of clarity in the wording of the statement, and differing perspectives on where responsibility for investments should lie. In addition, respondents identified a need for more research to generate evidence on the effectiveness and value for money of different interventional strategies.

Responses to B15 remained just below our consensus level (78.6\% agreement), but discussion at the workshop suggested that this may reflect a lack of understanding of the work of child death overview panels (CDOP) and 
Table 1 Socio-demographic characteristics of participants

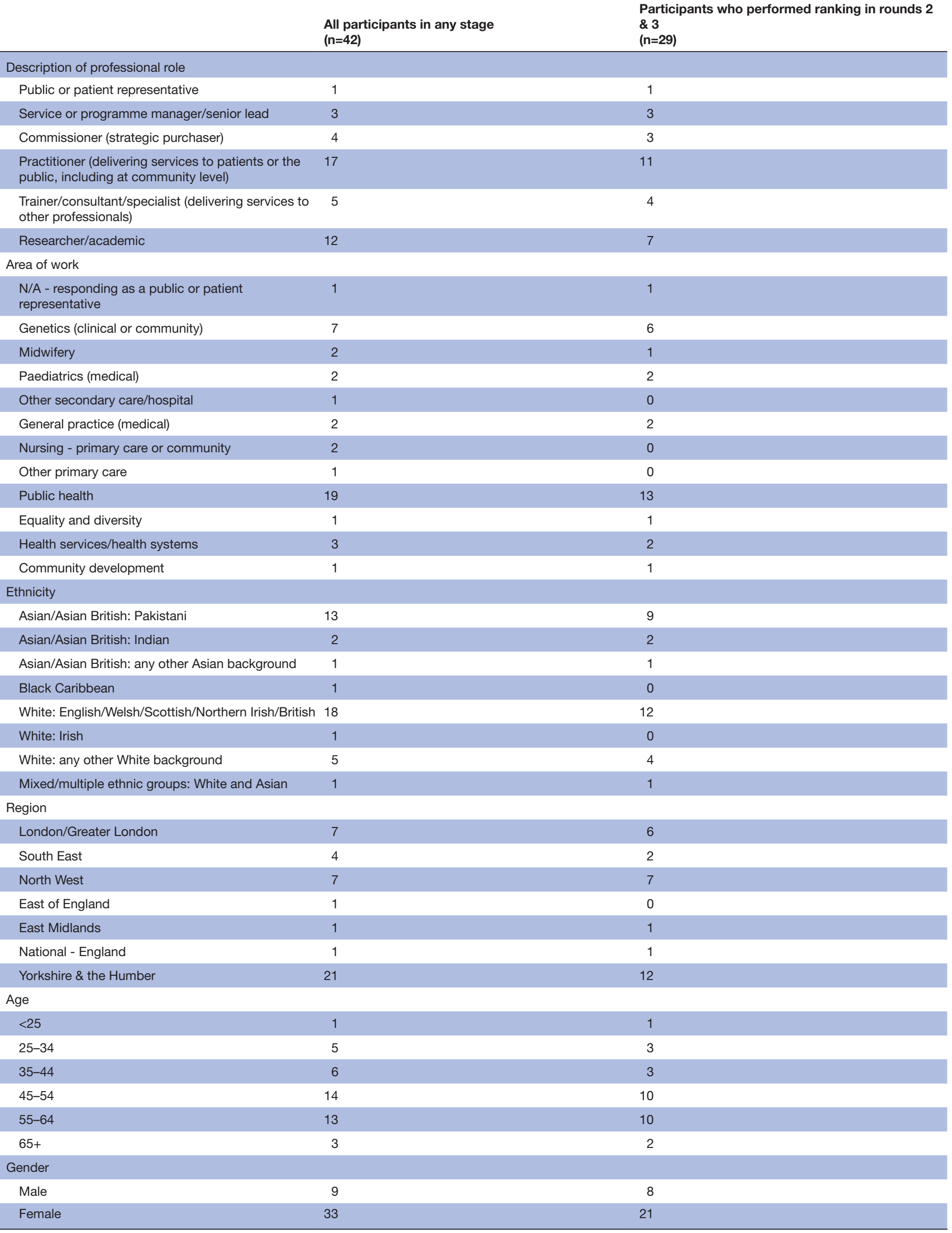




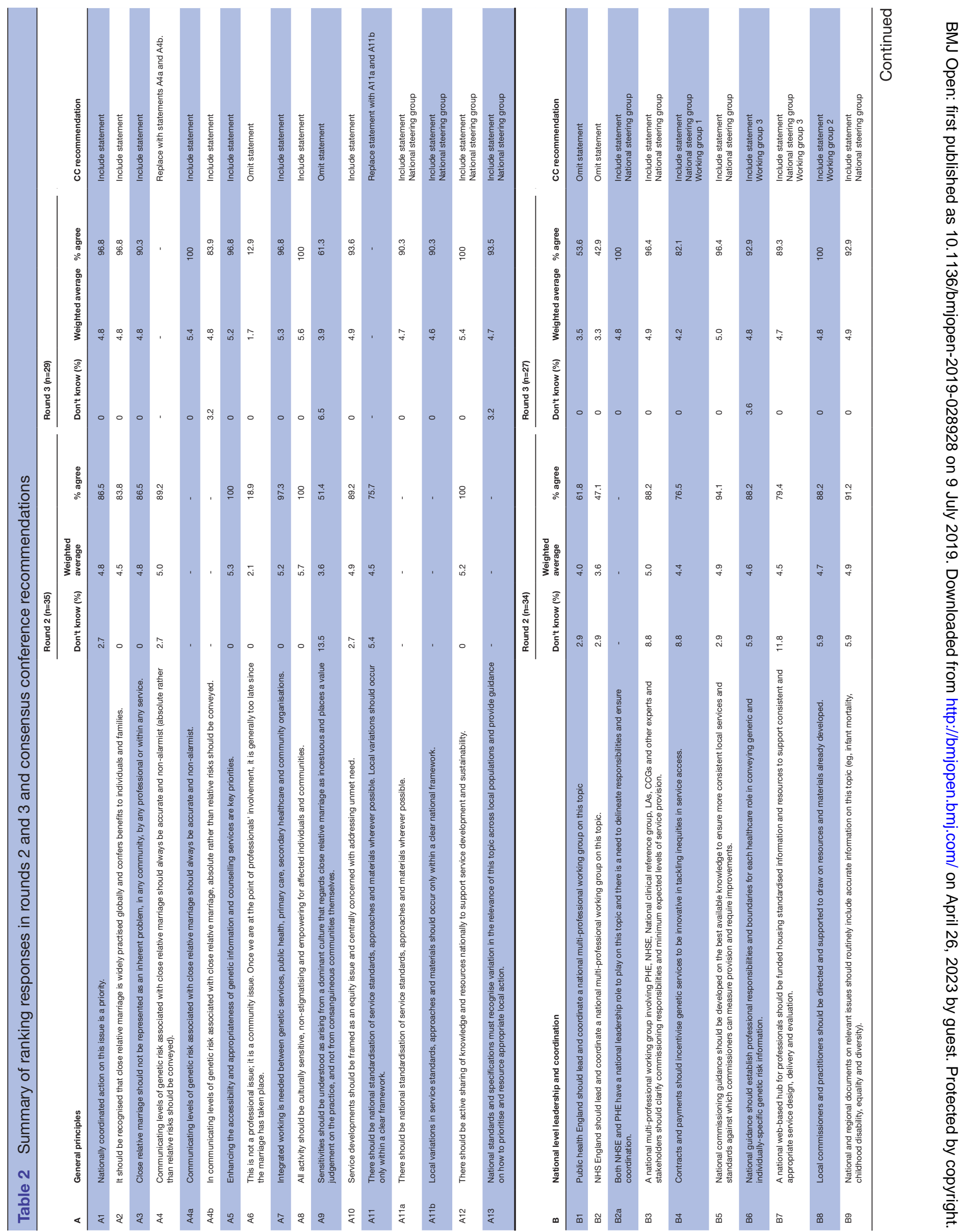




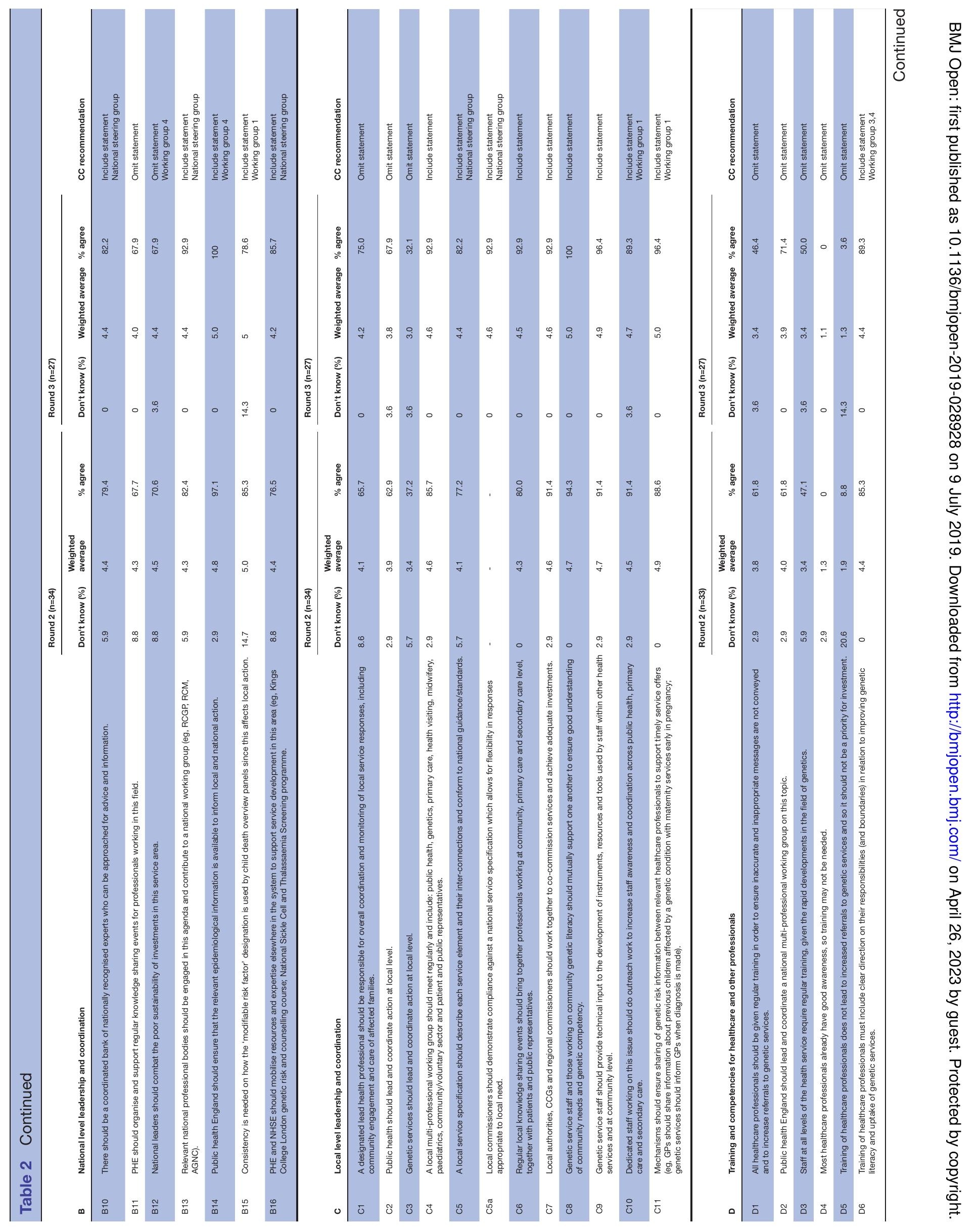




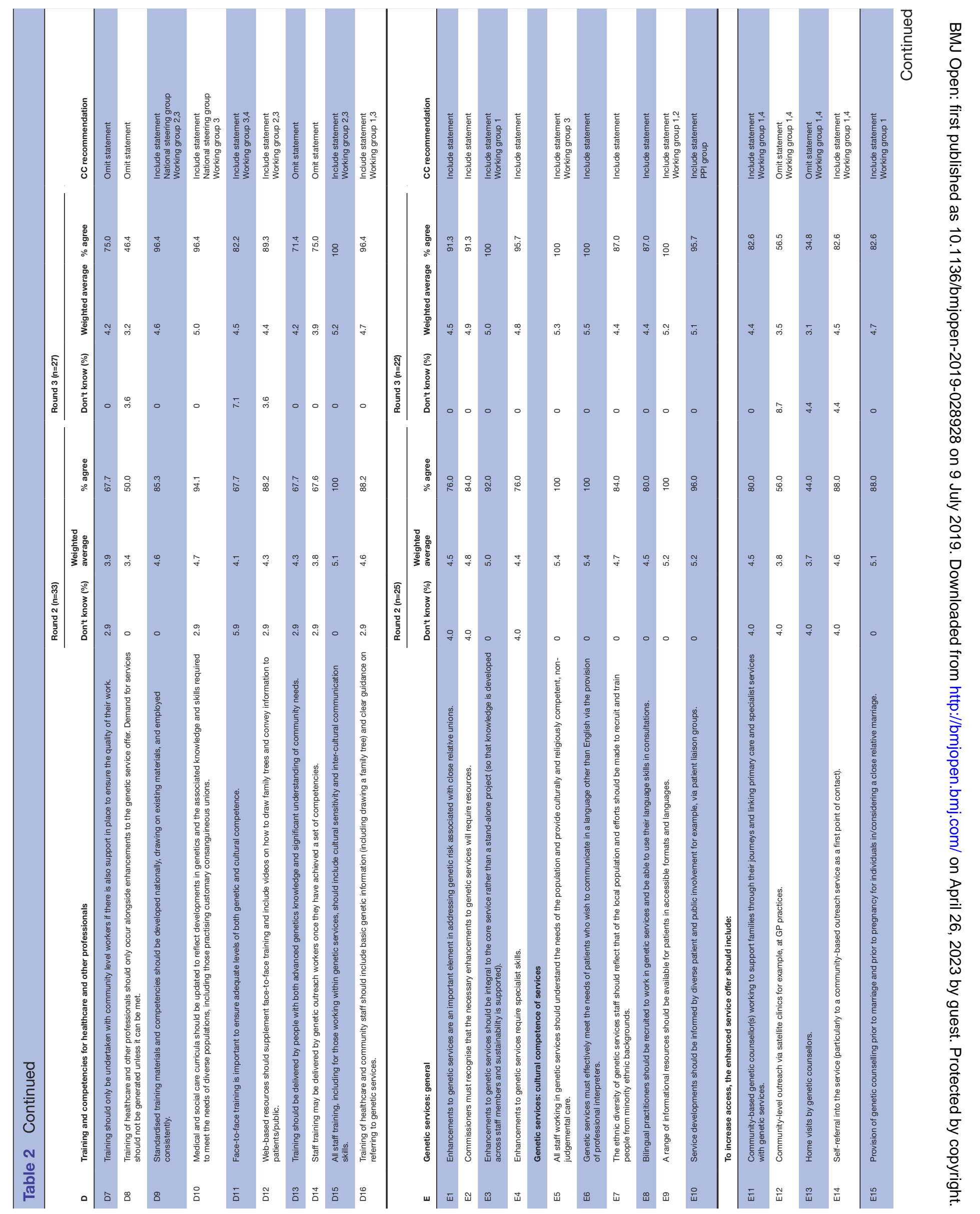




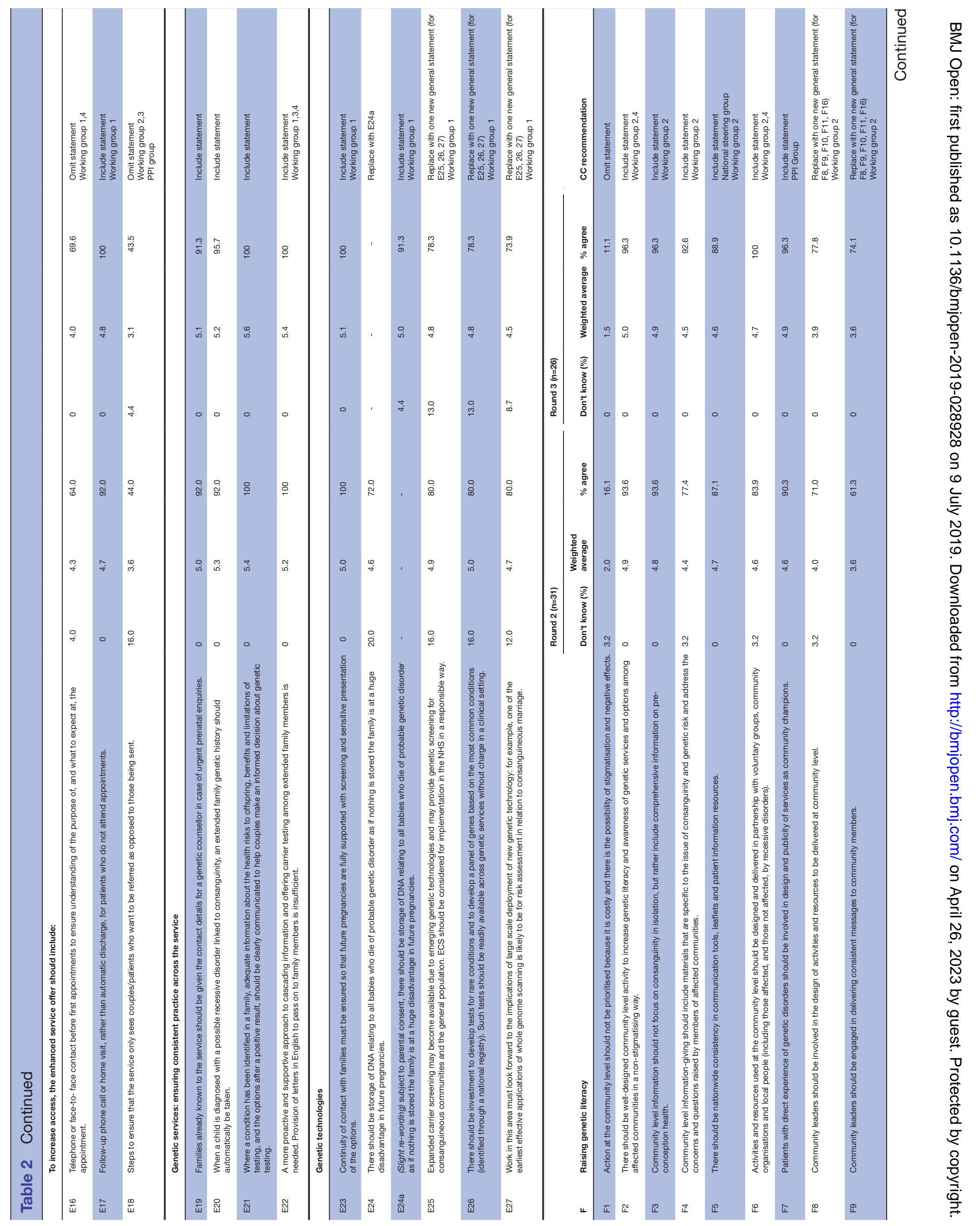




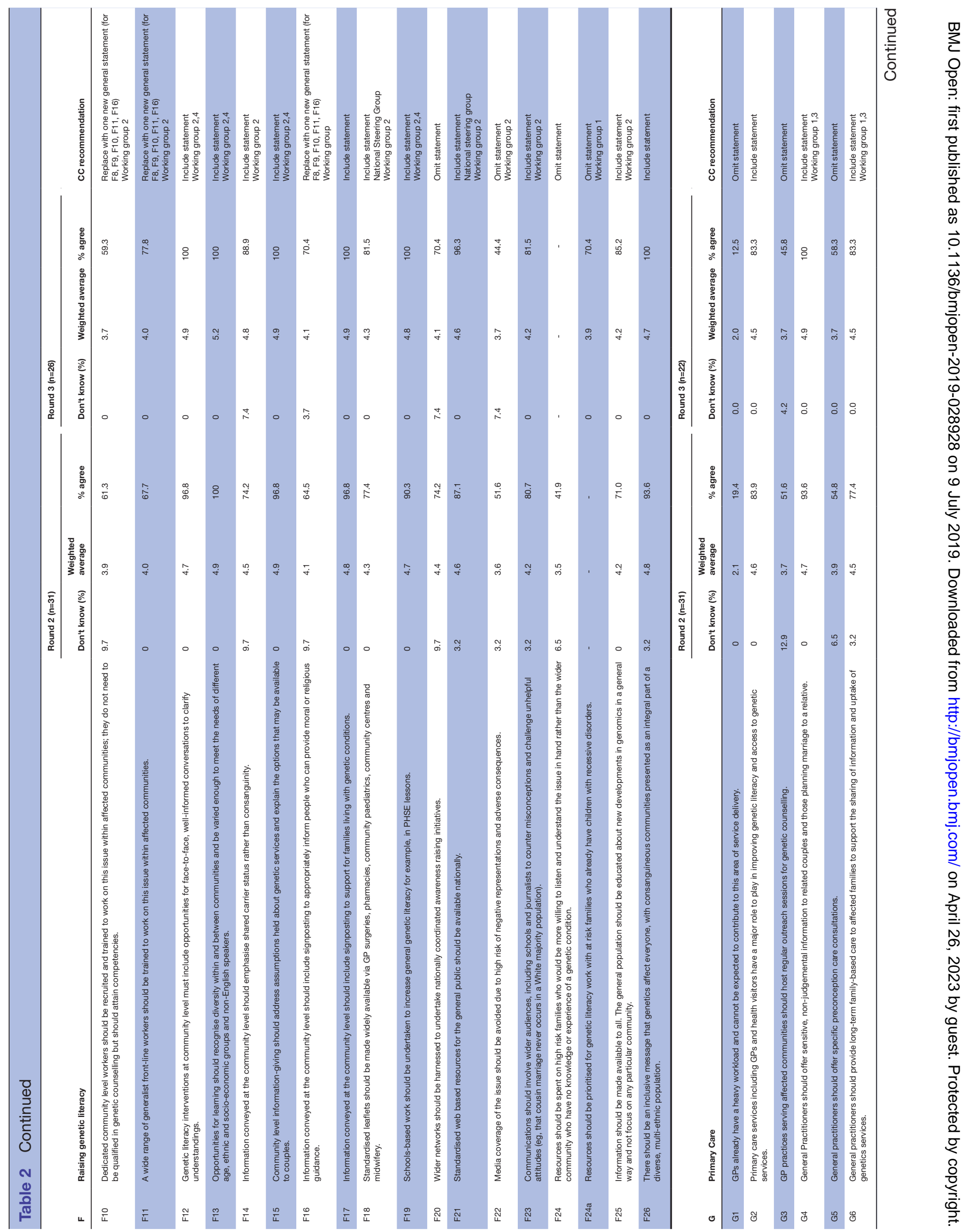




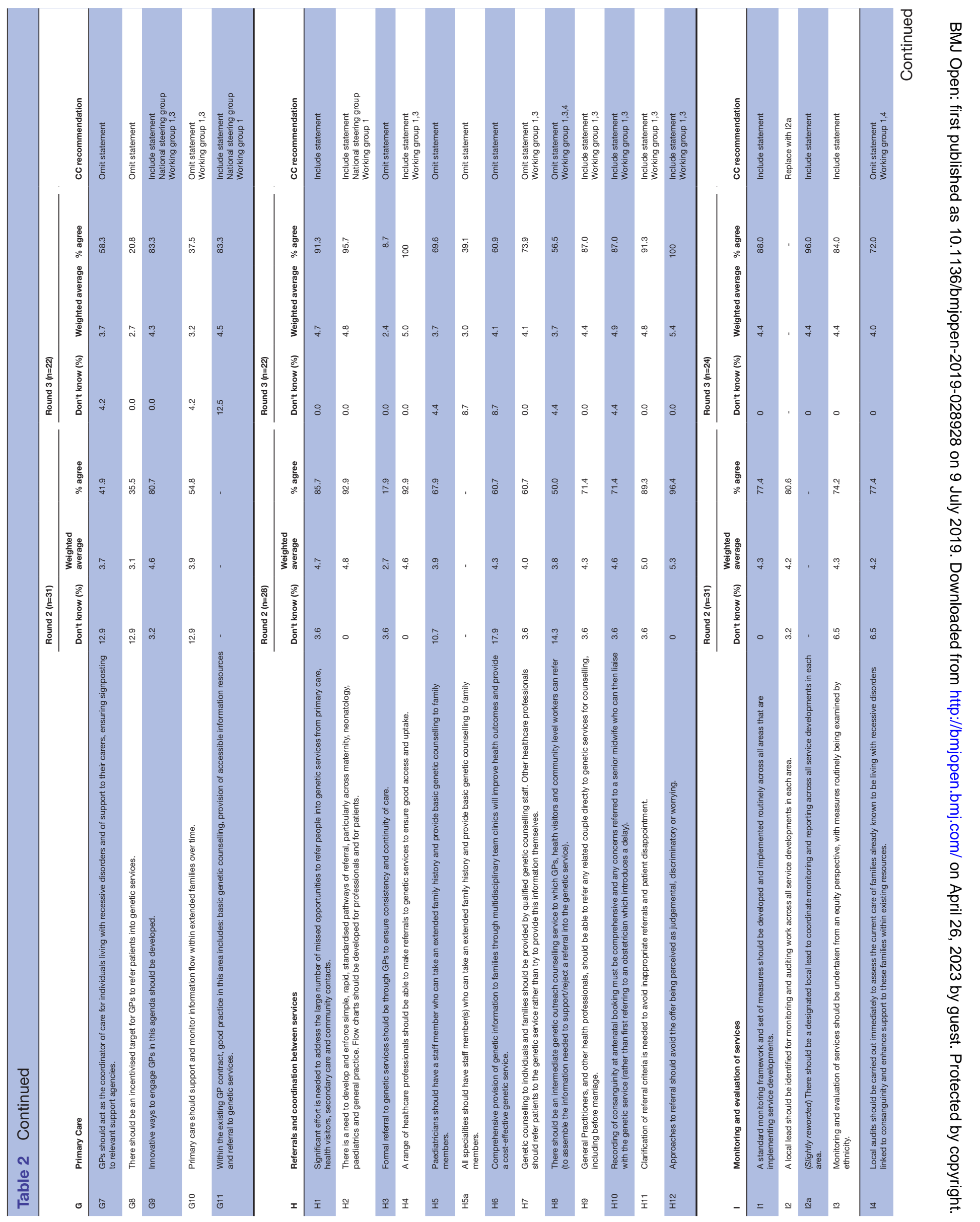




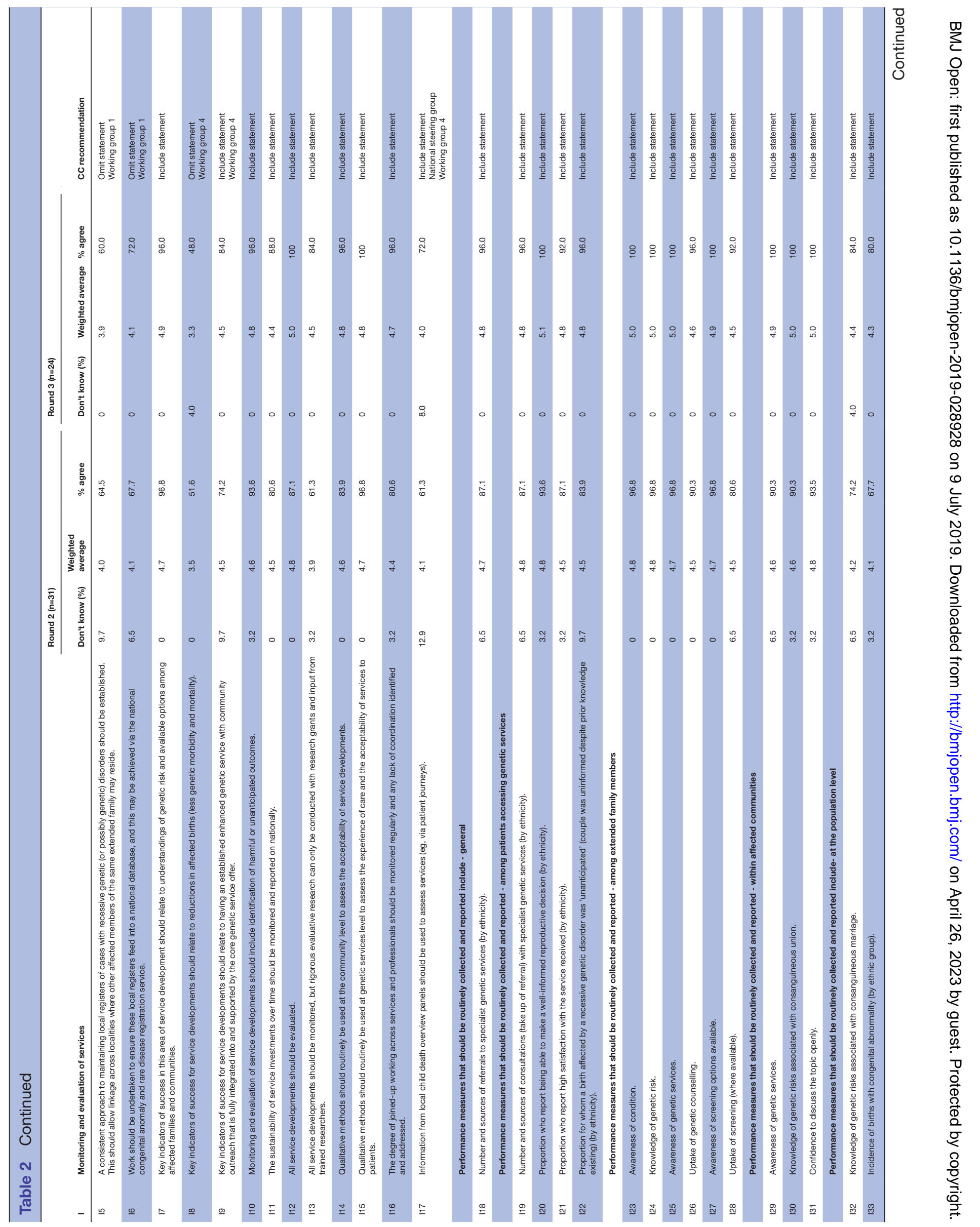




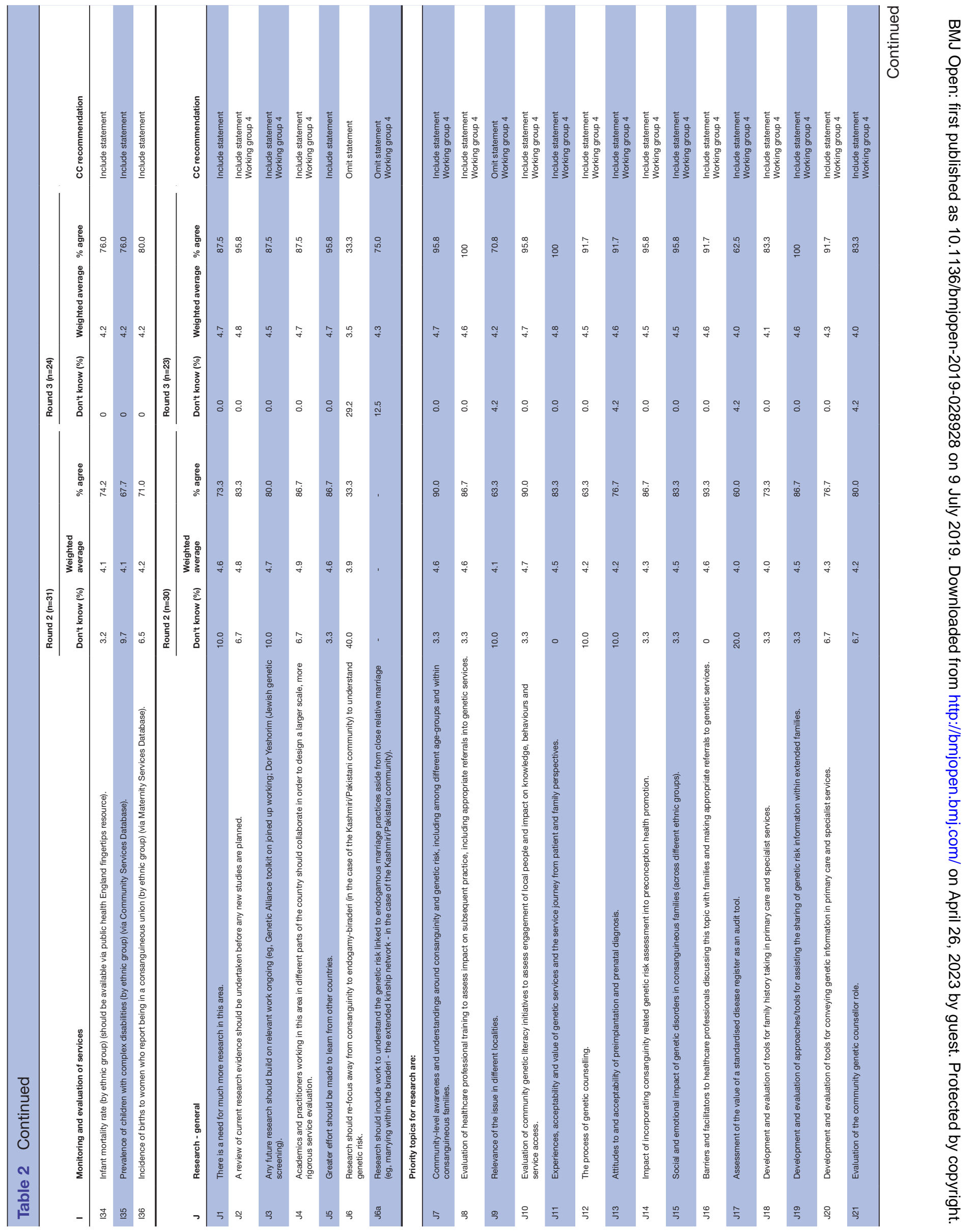




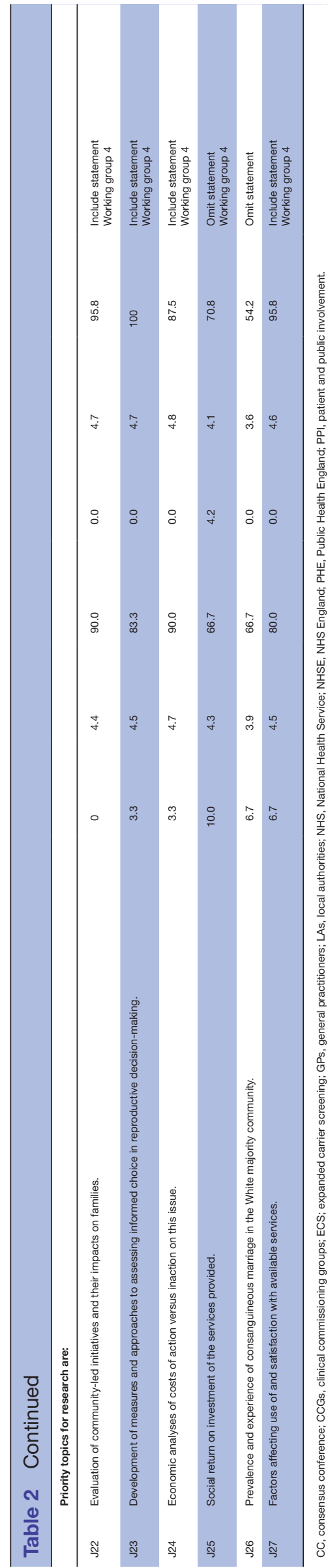

how the term 'modifiable risk factor' is employed in that context. Conference participants agreed that it was important to gain consistency in this area and that the CDOP national network would be an important group to engage in future work, particularly since CDOPs are statutory and therefore a potential tool for prompting action.

\section{Local level leadership and coordination}

In Round 3, nine out of the 12 statements reached consensus, with seven gaining over 90\% agreement. Responses to statements relating to which specialities should lead and coordinate service responses at local level failed to reach consensus (C1: $75.0 \%$ agreement, C2: $67.9 \%$ agreement and C3: $32.1 \%$ agreement). However, C4 - which calls for a local multi-agency group - was supported by $92.9 \%$ of respondents, mirroring the responses to the national-level statements that endorsed a collective responsibility and coordinated action across a wide group of stakeholders.

Consensus conference discussions confirmed that participants believed the establishment of local level multi-professional working groups with broad representation including public health and genetic services, as well as other professions and patient and public representatives, was key to making progress on this agenda. Participants talked of a 'whole system approach' and a commitment to multi-agency working. In addition, however, it is important to note that there were significant concerns around limited resources, which seemed to feed into the reluctance to place responsibility firmly with any particular organisation/function (eg, local authority public health or genetic services). Participants suggested that the identity of the person leading such a group should be determined locally depending on resources and expertise available.

Other statements in this theme that achieved consensus underscore the felt need for coordinated action and the sharing of skills and expertise across organisations. In keeping with the new statement A11b, in this theme a new statement C5a was introduced Local commissioners should demonstrate compliance against a national service specification which allows for flexibility in responses appropriate to local need' (92.9\% agreement), reflecting the recognition of the need for some local adaptation within a national framework.

\section{Training of healthcare and other staff}

In Round 3, just nine out of 16 statements in this theme achieved consensus, indicating significant levels of disagreement. Importantly, there was good consensus around the general statements that endorsed the need to train healthcare professionals. In particular, no participants agreed with the statement D4 'Most healthcare professionals already have good awareness, so training may not be needed', and all participants agreed with D15 'All staff training, including for those working within genetics services, should include cultural sensitivity and inter-cultural communication skills.' The statements that failed to achieve 
consensus were more specific in terms of who should be trained or who should deliver training.

Consensus conference participants felt that the failure of several statements in this theme to reach consensus was due to a lack of clarity (D1, D3, D7, D13, D14) or to two issues being covered in one statement (D2, D8). For instance, it was unclear what the term 'advanced' meant in statement D13. There was agreement that healthcare professionals do need to be trained in this area, but that there is work to be done to clarify the curriculum content, learning objectives and model for delivery of such training for different cadres of worker. Likewise, it was agreed that staff working at neighbourhood level in health and wellbeing or community development roles are a potential resource, but that a consistent, appropriate curriculum and model of training are yet to be developed (see genetic literacy section below). It was agreed that genetic services staff have an important role to play in developing curricula and supporting their delivery at local level. It was also agreed that there is a need to evaluate the impact of training on the practice of healthcare professionals and community level workers, particularly in terms of the extent to which they increase the number of appropriate referrals into genetic services.

\section{Genetic services}

As in Round 2, 20 out of 27 statements achieved consensus at the $80 \%$ cut-off level in Round 3. All four of the general statements relating to the need to enhance the genetic service offer achieved over $90 \%$ agreement, as did all the statements relating to steps to be taken to increase the cultural competence of genetic services, and all those relating to consistent practice for patients within the service. There was less agreement in responses to some of the more specific statements that set out how access to services should be improved.

Participants in the consensus conference gave careful consideration to all the statements that had low agreement. Statements E12 and E13 related to satellite clinics and home visits respectively; strategies aimed at increasing access to genetic services. Participants felt that the low level of agreement reflected both a concern about how realistic such strategies might be in the current resource climate and also a lack of evidence on how effective such strategies are at increasing service uptake. These were identified as areas in need of further research. Statement E16 - relating to pre-appointment contact - was felt to be poorly worded and it was pointed out that a pre-consultation phone call is already part of the genetic service specification. It was acknowledged that there is a need for more research on what types of pre-clinic contact or preparatory work are effective at improving clinic appointment attendance and quality. Statement E18 - 'Steps to ensure that the service only sees couples/patients who want to be referred as opposed to those being sent' - was felt to lack clarity, but participants agreed that more needs to be done to ensure that people who receive referrals to the genetic service understand the offer and are adequately prepared. This was identified as an area where co-production of informative materials with patients and members of the public could be helpful. Three statements relating to new genetic technologies, E25, E26 and E27 achieved just less than $80 \%$ agreement. Workshop participants noted the large proportion of 'don't know' responses and suggested that the answers did not reflect important differences of opinion or perspective. In addition, however, they noted the important distinction between technology application for families that already have an affected child, and those couples who might want to know their risk of having an affected child in advance where no specific condition has yet been identified for the family. In the latter case, there will often be no genetic testing that can be offered at the current time. Participants emphasised that this is a distinction that all staff who are engaged in the area should be aware of since there is evidence of patients and members of the public being misled by practitioners and the media into thinking that it is a simple process to 'screen' couples to detect shared deleterious recessive genes. At the same time, participants noted the importance of ensuring that, as technology advances, access to new testing procedures is equitably distributed and that this will require new protocols to ensure that individuals and families are monitored over time and re-referred into genetic services as-and-when opportunities for testing arise.

\section{Raising genetic literacy}

In this theme, 18 out of 27 statements achieved $80 \%$ agreement or higher, with others being close to the consensus cut-off (F8, F11). There was good agreement on the generic statements relating to the importance of implementing well-designed, non-stigmatising community level genetic literacy interventions (F2), and that these should be designed and delivered in partnership with local patients and members of the public (F6, F7). There was also good agreement on the content of genetic literacy messages (F14, F15, F17, F18, F21, F26). However, responses to some statements revealed significant disagreement among respondents. For instance, F10 - referring to the recruitment, training and deployment of dedicated community level workers who were not trained in genetic counselling but attained competencies - achieved only $59.3 \%$ agreement, while F22 which referred to avoiding the use of media coverage, achieved only $44.4 \%$ agreement. The new statement F24a'Resources should be prioritised for genetic literacy work with at risk families who already have children with recessive disorders', achieved $70.4 \%$ agreement - far higher than the $29.6 \%$ agreement with statement F24 which suggested only focusing on high risk families. Nevertheless, the lack of consensus indicates a reluctance among a significant proportion of respondents to reserve genetic literacy work for affected families alone.

Consensus conference discussions around this set of statements revealed some important areas of disagreement and a need for greater nuance in some of the principles. In relation to statements F8, F9, F10 and F11 
that refer to who should be delivering genetic literacy messages at community level, participants felt that the differing responses reflected divergent past experiences. For instance, the engagement of community leaders (F8 and F9) may have been a positive experience in some places but less so elsewhere. F8 and F9 were also statements that showed noteworthy divergence in agreement between the ethnic categories (eg, F8 Asian/Asian British Pakistani: 42.9\% agreement vs White British: $90.9 \%$, Fisher's exact test one-tailed $\mathrm{p}=0.047$, two-tailed $\mathrm{p}=0.095$ ) and the professional categories (eg, F9 public health: $100 \%$ agreement vs non-public health: $57.1 \%$, Fisher's exact test one-tailed $\mathrm{p}=0.013$, two-tailed $\mathrm{p}=0.026$ ), again suggesting differing perspectives and experiences. Participants at the consensus conference suggested that there was a need to specify the different models that have been used in different places more clearly and to evaluate their processes and outcomes. It seems likely that a variety of models could be effective, but that there is a need to isolate the key characteristics of successful approaches and to highlight potential dangers to be guarded against, so that approaches can be tailored to local contexts.

Discussion around F22 - avoidance of media coverage - confirmed that there are differing perspectives on this issue and that this relates at least in part to past negative experiences in some localities. It was agreed that there could be no consensus principle on whether or not the media should be actively engaged in local genetic literacy initiatives, but that there was a need for professionals to be able to respond to media enquiries confidently and consistently. Similarly, responses to F24 and F24a were felt to reflect differing perspectives, with some stakeholders placing focus on inadequate access to information and services among affected families and others seeking a more preventative, community-wide approach (often with an emphasis on seeking to increase community engagement and ownership of the issue). It is noteworthy that F24a that advocates the prioritisation of resources for genetic literacy work with at risk families identified with recessive disorders - received different levels of agreement between the professional groups (non-public health: $85.7 \%$ agreement vs public health: $50.0 \%$, though this difference was not statistically significant - Fisher's exact test one-tailed $\mathrm{p}=0.061$, two-tailed $\mathrm{p}=0.122$ ). In an ideal world, resources would be sufficient to deliver appropriate genetic literacy interventions to both groups. Some consensus conference participants also noted with interest the $100 \%$ agreement with statement F19 - that schools-based work should be undertaken to increase genetic literacy - given that there has been limited practice in this area and no evaluative work to-date and the potential for stigmatisation of pupils of minority ethnicity is recognised.

\section{Primary care}

In Round 3, six out of 11 statements relating to primary care achieved consensus. G11 was introduced as a new statement and achieved $83.3 \%$ agreement, indicating strong endorsement for general practice to play a clear role in this area of service provision - 'Within the existing GP contract, good practice in this area includes: basic genetic counselling, provision of accessible information resources and referral to genetic services.' G2 sends a similarly strong message 'Primary care services including GPs and health visitors have a major role to play in improving genetic literacy and access to genetic services' (83.3\% agreement). However, a number of statements that advocated more specific roles that general practice should play retained a low level of agreement.

The consensus conference participants felt that some of the statements that lacked consensus should not be rejected out of hand, but rather should become areas for future research and development work, for example, G10 'Primary Care should support and monitor information flow within extended families over time.'

\section{Referral and coordination}

In Round 3, eight out of 13 statements reached the $80 \%$ consensus cut-off. There was strong consensus that many opportunities to refer eligible patients for genetic counselling are currently missed (H1) and that work is needed to develop and enforce referral pathways from a range of healthcare professionals into genetic services (H2, H4, H9, H11). There was much less agreement around the statements relating to the type of genetic knowledge that particular healthcare professionals should have and the roles they should play in the provision of genetic information to patients (H5, H5a, H6, H7, H8).

Discussions during the consensus conference confirmed that the areas of disagreement reflected differing opinions about who should be equipped and able to routinely provide what type of genetic healthcare to patients in what contexts. Participants noted the wider push within English health policy to make genetics 'everyone's business', but pointed out that there are concerns about: resource implications, the quality of the information provided by generalists and the lack of evidence around which models are effective and good value for money. Discussions also suggested that issues of professional identity and boundary maintenance might also be at play here, with genetic counsellors in particular being wary of encroachment into their territory of expertise. On the other hand, participants acknowledged the current shortages of genetic counsellors and genetic consultants and the difficulties in recruiting to these posts. Participants agreed that work is needed to clarify how a wider range of health professionals can best contribute to improved access to genetic healthcare in general, and for marginalised communities including those practising customary consanguineous marriage in particular.

\section{Monitoring and evaluation}

Statements within this theme included 17 general statements and a further 19 that related to proposed measures that could be used to monitor the success of service responses in this area. Overall, 29 out of 36 statements achieved consensus. In terms of the general statements, 
there was strong agreement on the need for a standard monitoring framework to be implemented across local areas (I1, I2) and that monitoring should have a focus on equity (I3), increased understanding among affected families and communities (I8) and the integration, coordination and sustainability of new developments (I9, I11, I16). There was also agreement that the identification of harmful or unanticipated outcomes should be part of routine monitoring activity (I10), and that the use of qualitative methods should be used to assess experience and acceptability of services (I14, I15). Participants also strongly endorsed the need for evaluation of service developments (I12, I13).

There was, however, a lack of consensus on a set of statements that related to local auditing and local and national maintenance of registers of cases with confirmed or probable recessive genetic conditions (I4, I5 and I6). There was also no consensus on statement I8, with $48.0 \%$ of respondents agreeing that a key indicator of success for service developments should be reductions in affected births. This area of disagreement was mirrored by a lack of consensus on two of the proposed performance measures - I34 relating to infant mortality and I35 relating to prevalence of children with complex disabilities; though in both cases, $76 \%$ of respondents agreed with the statement. All of the other proposed measures for routine monitoring of services achieved $80 \%$ or greater agreement.

Discussions at the consensus conference indicated important variation in perspectives and levels of understanding across professional groups in relation to why and how local auditing of cases might be undertaken and how these might feed into a national register (I4, I5 and I6). It was concluded that a working group is needed to clarify procedures and their rationale in relation to both improving care for individuals and families and increasing understanding of the prevalence of particular conditions at a population level. Conference discussions of statements I8, I34 and I35 concluded that divergent perspectives exist on whether or not service development success should be measured in terms of reductions in affected births and associated morbidity and mortality. Participants suggested that measures of success should be focused on informed reproductive choice, but that it is also important to monitor the numbers of affected births, infant mortality and morbidity, so that I8 should be omitted, but I34 and I35 should be retained in the final set of statements.

I17, which referred to the use of information from child death overview panels to assess services also failed to reach $80 \%$ agreement, but the consensus conference discussions highlighted the high proportion of 'don't knows' and concluded that involving the national CDOP network in future policy and service developments was important so that more consistent practice can be developed.

\section{Research}

Round 3 produced consensus on 23 out of 28 statements relating to research principles and priorities. There was strong agreement that more research is needed and that greater effort should be made to learn from other countries and other related strands of work. A wide range of priority topics for research were agreed, relating to: understanding patient perspectives and experiences (J11, J12, J13,J15, J27), exploring healthcare professional roles and training $(\mathrm{J} 8, \mathrm{~J} 16)$, evaluating community-level activity (J7, J10, J22), developing and assessing new practice tools and approaches $(\mathrm{J} 14, \mathrm{~J} 18, \mathrm{~J} 19, \mathrm{~J} 20, \mathrm{~J} 21, \mathrm{~J} 23)$ and economic evaluation (J24).

Despite introducing a new statement, neither J6a (75.0\% agreement) nor J6 (33.3\% agreement) - which called for research on endogamy rather than consanguinity - achieved consensus. Other statements that failed to reach consensus were: J9 relating to researching the relevance of the issue across localities ( $70.8 \%$ agreement), $\mathrm{J} 17$ relating to assessing the value of a standardised disease register (62.5\% agreement) and J26 relating to the prevalence and experience of consanguineous marriage in the White majority community ( $54.2 \%$ agreement).

\section{Identification of next steps to moving the consensus statements into action}

The consensus conference small group and plenary discussions enabled the identification of next steps towards the production of a national set of principles and broader guidance for policy and practice.

Within each thematic area, statements that reached consensus fell into three categories: those that were deemed to be general principles that speak for themselves, those that referred to current standard practice but were nevertheless worth re-emphasising and those that required further working group deliberation and/or research to be developed into policy or practice guidance.

Those statements on which $80 \%$ agreement had not been reached, fell into four categories: those that should be omitted and not pursued further, those that should be omitted currently but that warranted further attention to clarify misconceptions, produce better evidence and/or achieve consensus, those that should be replaced with an alternative more generic statement to highlight the issue but which required working group deliberation and/or more research to develop into policy/practice guidance and four statements - B15, I17, I34 and I35 - that were felt to warrant inclusion and further development work, despite agreement falling just below the $80 \%$ threshold.

Importantly, an overarching theme of the exercise was the need for national level action and coordination, and the consensus conference participants concluded that the formation of a national steering group with representation from key national agencies was a priority action. In addition, the establishment of national level patient and public involvement group to guide all future activity was felt to be an essential complement. A series of linked working groups were proposed to take forward the work needed to further clarify and translate the statements into policy and practice guidance (figure 2). 


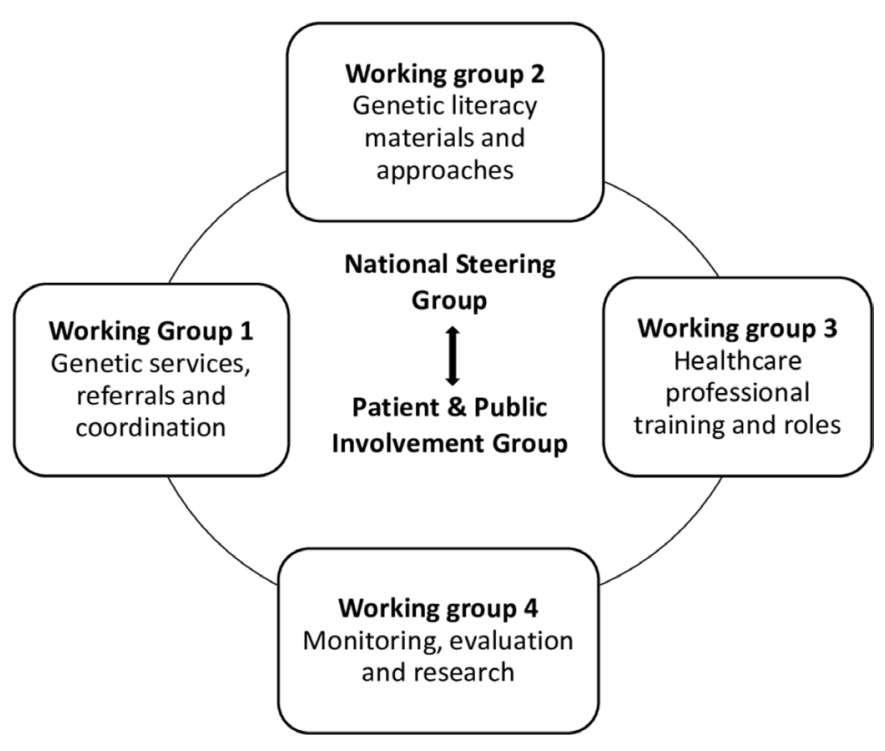

Figure 2 Structure of proposed working groups.

Table 2 (panels A-J) above identify the proposed next step for each statement put forward. Box 1 presents the final consolidated set of 148 agreed statements proposed for inclusion in a national set of principles.

\section{DISCUSSION}

\section{Principal findings}

The present study has confirmed that a wide range of healthcare professionals and other stakeholders recognise the need to develop more consistent policy and practice in response to the genetic risk associated with customary consanguineous marriage. Further, there is a high degree of agreement on the key principles that should shape such a response. Several core messages are encapsulated in the principles that achieved high levels of agreement. First, national leadership on this issue is considered important. Delphi participants emphasised the need for the DHSC to provide a clear mandate to NHS England and Public Health England to assume national level leadership through an inter-professional steering group that also engages other national agencies and professional bodies. National leadership and coordination was felt to be important to ensure consistency and efficiency in the development of policy and practice responses. Second, at local level, a joined-up, inter-professional response is needed, with general practitioners, health visitors, midwives and other healthcare professionals making important contributions alongside genetic services, public health and community-level organisations. Third, consensus statements emphasise the importance of framing policy and practice responses as fundamentally about increasing equity of access to healthcare and enhancing informed reproductive choice. Linked to this, the importance of ensuring culturally competent, non-stigmatising responses is emphasised, along with the need to develop ways of actively engaging affected individuals and communities in the co-design of services. Finally, recognising the emergent nature of service developments in this area, there is a recognised need to embed evaluation into new initiatives, to actively share knowledge and to undertake rigorous research to establish effective and good value practice in several areas. As well as these overarching principles that recur throughout the statements, many more specific expectations are set out that provide clear direction to both policy-makers and practitioners (box 1).

In addition, study findings suggest a number of areas where there is less agreement, some reflecting underlying differences in perspective, and others the need for more research evidence to inform practice. Areas of divergence in perspectives and contention that should be kept clearly in view as development work proceeds, include: whether the success of investments in this area should be assessed in terms of reductions in morbidity and mortality, whether and how 'community leaders' should be involved in initiatives, the roles and boundaries of non-specialist practitioners in providing genetic healthcare and the relative prioritisation of investments in services for families already identified as carrying deleterious gene variants versus broader, community-level genetic literacy initiatives.

\section{Strengths and weaknesses of the study}

A key strength of this study is its novelty. To our knowledge, this is the first study globally to examine health professional and other stakeholder opinions on how policy and practice should be developed in this area of need. As such, the findings fill an important knowledge gap. Furthermore, participants came from a wide range of backgrounds, including stakeholders beyond the health service, those that have close contact with affected communities in their work role, and those who self-identified as British Asian/Asian Pakistani (the largest ethnic group affected by this health need in the UK) and the response and retention rates were good. Many and diverse initial statements were successfully generated. The inclusion of a deliberative, consensus conference was also a strength in that it allowed the interrogation of statements lacking agreement and pragmatic discussion on appropriate next steps, thereby giving greater confidence that the achieved set of principles will provide an effective platform for subsequent action. Written feedback from participants at the consensus conference was overwhelmingly positive. A large number of Delphi participants expressed their desire to be involved in future working groups or kept informed of developments.

The participation of just one patient/public representative was a limitation. However, the four face-to-face public and patient consultation exercises undertaken at local level following completion of the Delphi were helpful in gaining feedback on the consensus statements and indicated broad endorsement. Future work must ensure meaningful inclusion of patient and public perspectives and insights. A further limitation was the persistence into the third round of several statements that lacked clarity.

\section{Relationship to earlier studies}

Several of the findings presented here are consistent with earlier recent work in the UK and elsewhere. The 
Box 1 Final consensus statements

\section{General principles}

1. Nationally coordinated action on this issue is a priority.

2. It should be recognised that close relative marriage is widely practised globally and confers benefits to individuals and families.

3. Close relative marriage should not be represented as an inherent problem, in any community, by any professional or within any service.

4. All activity should be culturally sensitive, non-stigmatising and empowering for affected individuals and communities.

5. Communicating levels of genetic risk associated with close relative marriage should always be accurate and non-alarmist.

6. In communicating levels of genetic risk associated with close relative marriage, absolute rather than relative risks should be conveyed.

7. Service developments should be framed as an equity issue and centrally concerned with addressing unmet need.

8. Enhancing the accessibility and appropriateness of genetic information and counselling services are key priorities.

9. Integrated working is needed between genetic services, public health, primary care, secondary healthcare and community organisations.

10. There should be national standardisation of service standards, approaches and materials wherever possible.

11. There should be an active sharing of knowledge and resources nationally to support service development and sustainability.

12. National standards and specifications must recognise variation in the relevance of this topic across local populations and provide guidance on how to prioritise and resource appropriate local action.

13. Local variations in service standards, approaches and materials should occur only within a clear national framework.

\section{National level leadership and coordination}

14. Both National Health Service (NHS) England and Pubic Health England have a national leadership role to play on this topic and there is a need to delineate responsibilities and ensure coordination.

15. A national multi-professional working group involving Pubic Health England, NHS England, national clinical reference group, local authorities, clinical commissioning groups and other experts and stakeholders should clarify commissioning responsibilities and minimum expected levels of service provision.

16. Contracts and payments should incentivise genetic services to be innovative in tackling inequities in service access.

17. National commissioning guidance should be developed on the best available knowledge to ensure more consistent local services and standards against which commissioners can measure provision and require improvements.

18. National guidance should establish professional responsibilities and boundaries for each healthcare role in conveying generic and individually-specific genetic risk information.

19. A national web-based hub for professionals should be funded housing standardised information and resources to support consistent and appropriate service design, delivery and evaluation.

20. Local commissioners and practitioners should be directed and supported to draw on resources and materials already developed.

21. National and regional documents on relevant issues should routinely include accurate information on this topic (eg, infant mortality, childhood disability, equality \& diversity)

22. There should be a coordinated bank of nationally recognised experts who can be approached for advice and information.

23. Relevant national professional bodies should be engaged in this agenda and contribute to a national working group (eg, Royal College of General Practitioners, Royal College of Midwives, Association of Genetic Nurses and Counsellors).

24. Public Health England should ensure that relevant epidemiological information is available to inform local and national action.

25. Consistency is needed on how the 'modifiable risk factor' designation is used by child death overview panels since this affects local action.

26. Public Health England and NHS England should mobilise resources and expertise elsewhere in the system to support service development in this area (eg, Kings College London Genetic Risk and Counselling Course; National Sickle Cell \& Thalassaemia Screening programme).

\section{Local level leadership and coordination}

27. A local multi-professional working group should meet regularly and include: public health, genetics, primary care, health visiting, midwifery, paediatrics, community/voluntary sector and patient and public representatives.

28. A local service specification should describe each service element and their inter-connections and conform to national guidance/ standards.

29. Local commissioners should demonstrate compliance against a national service specification which allows for flexibility in responses appropriate to local need.

30. Regular local knowledge sharing events should bring together professionals working at community, primary care and secondary care level, together with patients and public representatives.

31. Local authorities, clinical commissioning groups and regional commissioners should work together to co-commission services and achieve adequate investments.

32. Genetic service staff and those working on community genetic literacy should mutually support one another to ensure good understanding of community needs and genetic competency.

33. Genetic service staff should provide technical input to the development of instruments, resources and tools used by staff within other health services and at community level.

34. Dedicated staff working on this issue should do outreach work to increase staff awareness and coordination across public health, primary care and secondary care.

35. Mechanisms should ensure sharing of genetic risk information between relevant healthcare professionals to support timely service offers (eg, general practitioners (GPs) should share information about previous children affected by a genetic condition with maternity services early in pregnancy; genetics services should inform GPs when diagnosis is made). 


\section{Box 1 Continued}

Training and competencies for healthcare and other professionals

36. Training of healthcare professionals must include clear direction on their responsibilities (and boundaries) in relation to improving genetic literacy and uptake of genetic services.

37. Standardised training materials and competencies should be developed nationally, drawing on existing materials, and employed consistently.

38. Medical and social care curricula should be updated to reflect developments in genetics and the associated knowledge and skills required to meet the needs of diverse populations, including those practising customary consanguineous unions.

39. Face-to-face training is important to ensure adequate levels of both genetic and cultural competence.

40. Web-based resources should supplement face-to-face training and include videos on how to draw family trees and convey information to patients/public.

41. All staff training, including for those working within genetic services, should include cultural sensitivity and inter-cultural communication skills.

42. Training of healthcare and community staff should include basic genetic information (including drawing a family tree) and clear guidance on referring to genetic services.

Genetic services: general

43. Enhancements to genetic services are an important element in addressing genetic risk associated with close relative unions.

44. Commissioners must recognise that the necessary enhancements to genetic services will require resources.

45. Enhancements to genetic services should be integral to the core service rather than a stand-alone project (so that knowledge is developed across staff members and sustainability is supported).

46. Enhancements to genetic services require specialist skills.

Genetic services: cultural competence of services

47. All staff working in genetic services should understand the needs of the population and provide culturally and religiously competent, non-judgemental care.

48. Genetic services must effectively meet the needs of patients who wish to communicate in a language other than English via the provision of professional interpreters.

49. The ethnic diversity of genetic services staff should reflect that of the local population and efforts should be made to recruit and train people from minority ethnic backgrounds.

50. Bilingual practitioners should be recruited to work in genetic services and be able to use their language skills in consultations.

51. A range of informational resources should be available for patients in accessible formats and languages.

52. Service developments should be informed by diverse patient and public involvement for example, via patient liaison groups.

To increase access, the enhanced service offer should include:-

53. Community-based genetic counsellor(s) working to support families through their journeys and linking primary care and specialist services with genetic services.

54. Self-referral into the service (particularly for a community-based outreach service as a first point of contact).

55. Provision of genetic counselling prior to marriage and prior to pregnancy for individuals in/considering a close relative marriage.

56. Follow-up phone call or home visit, rather than automatic discharge, for patients who do not attend appointments.

Genetic services: ensuring consistent practice across the service

57. Families already known to the service should be given the contact details for a genetic counsellor in case of urgent prenatal enquiries.

58. When a child is diagnosed with a possible recessive disorder linked to consanguinity, an extended family genetic history should automatically be taken.

59. Where a condition has been identified in a family, adequate information about the health risks to offspring, benefits and limitations of testing and the options after a positive result, should be clearly communicated to help couples make an informed decision about genetic testing.

60. A more proactive and supportive approach to cascading information and offering carrier testing among extended family members is needed. Provision of letters in English to pass on to family members is insufficient.

\section{Genetic technologies}

61. Continuity of contact with families must be ensured so that future pregnancies are fully supported with screening and sensitive presentation of the options.

62. Subject to parental consent, there should be storage of DNA relating to all babies who die of the probable genetic disorder (as if nothing is stored the family is at a huge disadvantage in future pregnancies).

63. As genetic technologies develop attention to equity must be mainstreamed so that the benefits are harnessed for all families and communities, including those practising customary consanguineous marriage.

Raising genetic literacy

64. There should be nationwide consistency in communication tools, leaflets and patient information resources.

65. There should be well-designed community level activity to increase genetic literacy and awareness of genetic services and options among affected communities in a non-stigmatising way.

66. Local genetic literacy initiatives should be informed by prior evidence and based on a careful assessment of local assets and circumstances to determine the best approach to involving community leaders, generalist versus specialist outreach workers, local organisations and media.

67. Activities and resources used at the community level should be designed and delivered in partnership with voluntary groups, community organisations and local people (including those affected, and those not affected, by recessive disorders).

68. Patients with direct experience of genetic disorders should be involved in design and publicity of services as community champions.

69. Genetic literacy interventions at community level must include opportunities for face-to-face, well-informed conversations to clarify understandings. 


\section{Box 1 Continued}

70. Opportunities for learning should recognise diversity within and between communities and be varied enough to meet the needs of different age, ethnic and socio-economic groups and non-English speakers.

71. There should be an inclusive message that genetic conditions affect all communities, with consanguineous communities presented as an integral part of a diverse, multi-ethnic population.

72. Community level information should not focus on consanguinity in isolation, but rather include comprehensive information on pre-conception health.

73. Community level information-giving should include materials that are specific to the issue of consanguinity and genetic risk and address the concerns and questions raised by members of affected communities.

74. Information conveyed at the community level should emphasise shared carrier status rather than consanguinity.

75. Community level information-giving should address assumptions held about genetic services and explain the options that may be available to couples.

76. Information conveyed at the community level should include signposting to support for families living with genetic conditions.

77. Standardised web-based resources for the general public should be available nationally.

78. Standardised leaflets should be made widely available via GP surgeries, pharmacies, community paediatrics, community centres and midwifery.

79. Schools-based work should be undertaken to increase general genetic literacy for example, in personal, social \& health education lessons.

80. Communications should involve wider audiences, including schools and journalists to counter misconceptions and challenge unhelpful attitudes (eg, that cousin marriage never occurs in White majority populations)

81. Information should be made available to all. The general population should be educated about new developments in genomics in a general way and not focus on any particular community.

\section{Primary care}

82. Primary care services including general practitioners and health visitors have a major role to play in improving genetic literacy and access to genetic services.

83. Innovative ways to engage general practitioners in this agenda should be developed.

84. Within the existing GP contract, good practice in this area includes: basic genetic counselling, provision of accessible information resources and referral to genetic services.

85. General practitioners should offer sensitive, non-judgemental information to related couples and those planning marriage to a relative.

86. General practitioners should provide long-term family-based care to affected families to support the sharing of information and uptake of genetic services.

\section{Referrals and coordination between services}

87. Significant effort is needed to address the large number of missed opportunities to refer people into genetic services from primary care, health visitors, secondary care and community contacts.

88. There is a need to develop and enforce simple, rapid, standardised pathways of referral, particularly across maternity, neonatology, paediatrics and general practice. Flow charts should be developed for professionals and for patients.

89. A range of healthcare professionals should be able to make referrals to genetic services to ensure good access and uptake.

90. General practitioners, and other health professionals, should be able to refer any related couple directly to genetic services for counselling, including before marriage.

91. Clarification of referral criteria is needed to avoid inappropriate referrals and patient disappointment.

92. Approaches to referral should avoid the offer being perceived as judgemental, discriminatory or worrying.

93. Recording of consanguinity at antenatal booking must be comprehensive and any concerns referred to a senior midwife who can then liaise with the genetic service (rather than first referring to an obstetrician, which introduces a delay).

\section{Monitoring and evaluation of services}

94. A standard monitoring framework and set of measures should be developed and implemented routinely across all areas that are implementing service developments.

95. There should be a designated local lead to coordinate monitoring and reporting across all service developments in each area.

96. Monitoring and evaluation of services should be undertaken from an equity perspective, with measures routinely being examined by ethnicity.

97. Key indicators of success for this area of service development should relate to understandings of genetic risk and available options among affected families and communities.

98. Key indicators of success for service developments should relate to having an established enhanced genetic service with community outreach that is fully integrated into and supported by the core genetics offer.

99. Monitoring and evaluation of service developments should include identification of harmful or unanticipated outcomes.

100. The sustainability of service investments over time should be monitored and reported on nationally.

101. The degree of joined-up working across services and professionals should be monitored regularly and any lack of coordination identified and addressed.

102. All service developments should be evaluated.

103. Qualitative methods should routinely be used at the community level to assess the acceptability of service developments.

104. Qualitative methods should routinely be used at genetic services level to assess the experience of care and the acceptability of services to patients.

105. All service developments should be monitored, but rigorous evaluative research can only be conducted with research grants and input from trained researchers.

106. Information from local child death overview panels should be used to assess services (eg, via patient journeys). 
Box 1 Continued

Performance measures that should be routinely collected and reported include - general

107. Number and sources of referrals to specialist genetic services (by ethnicity).

Performance measures that should be routinely collected and reported - among patients accessing genetic services

108. Number and sources of consultations (take up of referral) with specialist genetic services (by ethnicity).

109. Proportion who report being able to make a well-informed reproductive decision (by ethnicity).

110. Proportion who report high satisfaction with service received (by ethnicity).

111. Proportion for whom a birth affected by a recessive genetic disorder was 'unanticipated' (couple was uninformed despite prior knowledge existing) (by ethnicity).

Performance measures that should be routinely collected and reported - among extended family members

112. Awareness of condition.

113. Knowledge of genetic risk.

114. Awareness of genetic services.

115. Uptake of genetic counselling.

116. Awareness of screening options available.

117. Uptake of screening (where available).

Performance measures that should be routinely collected and reported - within affected communities

118. Awareness of genetic services.

119. Knowledge of genetic risks associated with consanguineous union.

120. Confidence to discuss the topic openly.

Performance measures that should be routinely collected and reported include- at the population level

121. Knowledge of genetic risks associated with consanguineous marriage.

122. Incidence of births with congenital abnormality (by ethnic group).

123. Infant mortality rate (by ethnic group) (should be available via Public Health England fingertips resource).

124. Prevalence of children with complex disabilities (by ethnic group) (via Community Services Database).

125. Incidence of births to women who report being in a consanguineous union (by ethnic group) (via Maternity Services Database).

Research - general

126. There is a need for much more research in this area.

127. A review of current research evidence should be undertaken before any new studies are planned.

128. Any future research should build on relevant work ongoing (eg, Genetic Alliance toolkit on joined up working; Dor Yeshorim (Jewish genetic screening).

129. Academics and practitioners working in this area in different parts of the country should collaborate in order to design a larger scale, more rigorous service evaluation.

130. Greater effort should be made to learn from other countries.

Priority topics for research are:-

131. Community-level awareness and understandings around consanguinity and genetic risk, including, among different age-groups and within consanguineous families.

132. Evaluation of the community genetic counsellor role.

133. Evaluation of community-led initiatives and their impacts on families.

134. Evaluation of community genetic literacy initiatives to assess the engagement of local people and impact on knowledge, behaviours and service access.

135. Evaluation of healthcare professional training to assess impact on subsequent practice, including appropriate referrals into genetic services.

136. Barriers and facilitators to healthcare professionals discussing this topic with families and making appropriate referrals to genetic services.

137. Experiences, acceptability and value of genetic services and the service journey from patient and family perspectives.

138. Factors affecting use of and satisfaction with available services.

139. The process of genetic counselling.

140. Attitudes to and acceptability of preimplantation and prenatal diagnosis.

141. Impact of incorporating consanguinity-related genetic risk assessment into preconception health promotion.

142. Social and emotional impact of genetic disorders in consanguineous families (across different ethnic groups).

143. Assessment of the value of a standardised disease register as an audit tool.

144. Development and evaluation of tools for family history taking in primary care and specialist services.

145. Development and evaluation of approaches/tools for assisting the sharing of genetic risk information within extended families.

146. Development and evaluation of tools for conveying genetic information in primary care and specialist services.

147. Development of measures and approaches to assessing informed choice in reproductive decision-making.

148. Economic analyses of costs of action versus inaction on this issue.

consensus statements can be seen to be responding to the current inconsistent and poorly coordinated nature of local service responses and the importance of a multi-professional approach that have been documented elsewhere. ${ }^{20}$ Similarly, the focus on equity and cultural competence running through the statements is consistent with concerns highlighted in earlier research that affected populations face significant 
barriers to good quality services. ${ }^{13} 1423$ Some areas of divergence in perspectives highlighted above have also been suggested in earlier work, ${ }^{20}$ including the need to clarify how a wider range of health professionals can best contribute to improved access to genetic healthcare in general, and for marginalised communities, including those practising customary consanguineous marriage, in particular.

\section{Implications}

The study has generated a set of general principles (box 1) that provides immediate direction to policy-makers and healthcare professionals at national and local level in the UK. Further, the final set of consensus statements includes specific recommendations for actions to shape service responses in this area. These findings have immediate relevance to the development of the new English national genomic service and the future direction of the 100000 genome project. In addition, priority areas for further research and development have been highlighted. The exercise has also led to the identification of working groups through which these statements will be mobilised and translated into action in the coming months. The study outputs will be of wider interest to policy-makers, practitioners and health service researchers in other countries where the issue of genetic risk linked to customary consanguineous marriage among minority groups is recognised but remains poorly addressed. The approach we have taken here may also provide a model for those seeking to advance the development of policy and practice in other marginalised healthcare areas.

\section{CONCLUSIONS}

There is agreement across a range of UK stakeholders that national leadership and coordinated action is needed to develop consistent and appropriate policy and practice responses to the increased genetic risk associated with customary consanguineous marriage. There is also agreement that responses must: be framed as an equity issue, be multi-professional/multi-agency, be empowering for affected communities and involve investments to enhance access to genetic information and services alongside upskilling of professionals. Priority areas for further research and development and to establish operational guidance have been identified. These include work to develop tools that support the sharing of genetic information within affected families, and to establish effective models of community engagement in genetic literacy initiatives across diverse local settings. The results of this exercise should provide much-needed impetus to developing more consistent national policy and local practice in this area of unmet healthcare need.

\section{Author affiliations}

${ }^{1}$ Department of Sociological Studies, University of Sheffield, Sheffield, UK

${ }^{2}$ Manchester Centre for Genomic Medicine, St Mary's Hospital, Manchester University Hospitals NHS Foundation Trust, Manchester, UK
${ }^{3}$ School of Nursing and Midwifery, University of Sheffield, Sheffield, UK

${ }^{4}$ South West Thames Regional Genetics Service, St George's University Hospitals, London, UK

${ }^{5}$ Children and Young People's Public Health Team, Sheffield City Council, Sheffield, UK

${ }^{6}$ Division of Primary Care, University of Nottingham, Nottingham, UK

Acknowledgements We gratefully acknowledge the important contribution made by all participants in the Delphi exercise.

Contributors SS conceived the project and led the planning, design, conduct and reporting of the research. EY made a significant contribution to the design, planning, conduct and reporting of the research. NK, PA, FE and JT each made significant contributions to the design, conduct and reporting of the research. NQ made a significant contribution to the conduct and reporting of the research. All authors have approved the final version of the manuscript. The corresponding author attests that all listed authors meet authorship criteria and that no others meeting the criteria have been omitted.

Funding The authors have not declared a specific grant for this research from any funding agency in the public, commercial or not-for-profit sectors.

Competing interests None declared.

Patient consent for publication Not required.

Ethics approval Ethics approval for the study was granted by the University of Sheffield Research Ethics Committee (Reference Number 018838).

Provenance and peer review Not commissioned; externally peer reviewed.

Data sharing statement Data from rounds 1 to 3 have been archived and are available from the University of Sheffield research data catalogue and repository (ORDA), https://orda.shef.ac.uk.

Open access This is an open access article distributed in accordance with the Creative Commons Attribution Non Commercial (CC BY-NC 4.0) license, which permits others to distribute, remix, adapt, build upon this work non-commercially, and license their derivative works on different terms, provided the original work is properly cited, appropriate credit is given, any changes made indicated, and the use is non-commercial. See: http://creativecommons.org/licenses/by-nc/4.0/.

\section{REFERENCES}

1. Bittles A. Consanguinity in context: Cambridge University Press, 2012.

2. Bundey S, Alam H. A five-year prospective study of the health of children in different ethnic groups, with particular reference to the effect of inbreeding. Eur J Hum Genet 1993;1:206-19.

3. Sheridan E, Wright J, Small N, et al. Risk factors for congenital anomaly in a multiethnic birth cohort: an analysis of the Born in Bradford study. Lancet 2013;382:1350-9.

4. Jaber L, Halpern GJ, Shohat M. The impact of consanguinity worldwide. Community Genet 1998;1:12-17.

5. el-Hazmi MA, al-Swailem AR, Warsy AS, et al. Consanguinity among the Saudi Arabian population. J Med Genet 1995;32:623-6.

6. Jaber L, Merlob P, Bu X, et al. Marked parental consanguinity as a cause for increased major malformations in an Israeli Arab community. Am J Med Genet 1992;44:1-6.

7. Saleh M, Barlow-Stewart K, Meiser B, et al. An exploration of the cultural context of kinship and genetics amongst Arabic-Australians: implications for practice. J Genet Couns 2011;20:465-75.

8. Stoltenberg C, Magnus P, Lie RT, et al. Birth defects and parental consanguinity in Norway. Am J Epidemiol 1997;145:439-48.

9. Ten Kate LP, Teeuw ME, Henneman L, et al. Consanguinity and endogamy in the Netherlands: demographic and medical genetic aspects. Hum Hered 2014;77(1-4):161-6.

10. Becker R, Keller T, Wegner RD, et al. Consanguinity and pregnancy outcomes in a multi-ethnic, metropolitan European population. Prenat Diagn 2015;35:81-9.

11. Nybo Andersen AM, Gundlund A, Villadsen SF. Stillbirth and congenital anomalies in migrants in Europe. Best Pract Res Clin Obstet Gynaecol 2016;32:50-9.

12. Khan N, Benson J, Macleod R, et al. Developing and evaluating a culturally appropriate genetic service for consanguineous South Asian families. J Community Genet 2010;1:73-81.

13. Darr A, Small N, Ahmad WI, et al. Examining the family-centred approach to genetic testing and counselling among UK Pakistanis: a community perspective. J Community Genet 2013;4:49-57. 
14. Darr A, Small N, Ahmad WI, et al. Addressing key issues in the consanguinity-related risk of autosomal recessive disorders in consanguineous communities: lessons from a qualitative study of British Pakistanis. J Community Genet 2016;7:65-79.

15. Sharkia R, Tarabeia J, Zalan A, et al. Factors affecting the utilization of genetic counseling services among Israeli Arab women. Prenat Diagn 2015;35:370-5.

16. Buunk AP. All in the family: attitudes towards cousin marriages among young Dutch people from various ethnic groups. Journal of Evolutionary Psychology 2017;15:1-15.

17. Khan N, Kerr G, Kingston H. Community engagement and education: addressing the needs of South Asian families with genetic disorders. J Community Genet 2016;7:317-23.

18. Ajaz M, Ali N, Randhawa G. UK Pakistani views on the adverse health risks associated with consanguineous marriages. $J$ Community Genet 2015;6:331-42.

19. Alnaqeb D, Hamamy H, Youssef AM, et al. Assessment of knowledge, attitude and practice towards consanguineous marriages among a cohort of multiethnic health care providers in Saudi Arabia. J Biosoc Sci 2018;50:1-18.

20. Salway S, Ali P, Ratcliffe G, et al. Responding to the increased genetic risk associated with customary consanguineous marriage among minority ethnic populations: lessons from local innovations in England. J Community Genet 2016;7:215-28.

21. Ahmad W. Consanguinity and related demons: science and racism in the debate on consanguinity and birth outcome. In: Samson C South N, eds. The social construction of social policy. Macmillan, 1996:69-87.

22. Shaw A. Consanguineous marriage and the psychopathology of the progeny of first-cousin couples. JAMA Psychiatry 2018;75:426-7.

23. Shaw A. British Pakistani cousin marriages and the negotiation of reproductive risk, Chapter 5 in Shaw A, and Raz AE. Cousin marriages: Between tradition, genetic risk and cultural change. Berghahn Books 2015:114-29.

24. Qureshi N, Raeburn S. Risks to offspring of consanguineous marriage: we need straight, not crooked thinking. J $R$ Coll Physicians Edinb 2011;41:194-5.

25. Consanguineous marriage: keeping it in the family. The Economist. 2016 https://www.economist.com/middle-east-and-africa/2016/02/ 25/keeping-it-in-the-family (Accessed 14 Dec 2018).

26. Bittles A. Birth defect risk for children of first cousins is overstated. The Conversation. 2013 https://theconversation.com/birth-defect- risk-for-children-of-first-cousins-is-overstated-15809 (Accessed 14 Dec 2018)

27. Teeuw ME, Borry P. Preconception care for consanguineous couples in the Netherlands. Chapter 10 in Shaw A, and Raz AE (2015) Cousin marriages: Between tradition, genetic risk and cultural change. Berghahn Books 2015:202-217. 2015.

28. Alwan A, Modell B. Community control of genetic and congenital disorders. WHO Regional Office for the Eastern Mediterranean Technical Publication Series 24. 1997.

29. Modell B, Darr A. Genetic counselling and customary consanguineous marriage. Nat Rev Genet 2002;3:225-9.

30. Department of Health. Implementation plan for reducing health inequalities in infant mortality: a good practice guide. London: Health Inequalities Unit, Department of Health, 2007.

31. Department of Health. Tackling health inequalities in infant and maternal health outcomes: report of the infant mortality National Support Team. London: Health Inequalities Unit, Department of Health, 2010.

32. Department of Health. Building on our inheritance: genomic technology in healthcare: Human Genomics Strategy Group, Department of Health, 2012.

33. Ali PA, Salway S, Such E, et al. Enhancing health literacy through codesign: development of culturally appropriate materials on genetic risk and customary consanguineous marriage. Prim Health Care Res Dev 2019;20.

34. Qureshi N, Gilbert P, Raeburn JA. Consanguinity and genetic morbidity in a British primary care setting: a pilot study with trained linkworkers. Ann Hum Biol 2003;30:140-7.

35. Diamond IR, Grant RC, Feldman BM, et al. Defining consensus: a systematic review recommends methodologic criteria for reporting of Delphi studies. J Clin Epidemiol 2014;67:401-9.

36. Heather N, Dallolio E, Hutchings D, et al. Implementing routine screening and brief alcohol intervention in primary health care: a Delphi survey of expert opinion. J Subst Use 2004;9:68-85.

37. Thangaratinam S, Rogozinska E, Jolly K, et al. Effects of interventions in pregnancy on maternal weight and obstetric outcomes: meta-analysis of randomised evidence. BMJ 2012;344:e2088.

38. Halcomb E, Davidson P, Hardaker L. Using the consensus development conference method in healthcare research. Nurse Res 2008;16:56-71. 